\title{
ORE MINERALS UNDER THE MICROSCOPE
}

\section{By JAMES A. NOBLE}

\section{$\mathbf{T}$}

HE student of geology in the course of his training usually passes through three stages of achievement: A first in which he learns to identify the materials with which he works; a second in which he learns to recognize the distribution of these materials in space; and a third in which, from this distribution, he interprets the geologic history of the area of the assemblage of materials. Paraphrasing this generalization into words the student himself might use, he eventualy must answer these three questions: "What is it?", "Where is it?," and "How did it get that way?"

Certainly not all geologic study can be compressed into this simple formula, but the generalization fits several branches of applied geology. In particular, it adapts itself to the study of polished sections of ore minerals as a means of interpreting processes of ore deposition. Though a student may have progressed through the stage of identifying minerals and rocks in hand specimens and with the aid of a microscope, though he may have acquired proficiency in field mapping, and though he may have acquired some skill in the interpretation of the space relations, he is back at the beginning, in so far as the study of ore deposits is concerned, when he sees his first set of polished sections, for he has to learn to identify the minerals all over again.

This change in appearance of even the most familiar minerals when seen on the polished section results from the degree of polish which is needed in the study of opaque minerals. Because most of the ore minerals are essentially opaque in any thickness that can be conveniently handled, it is impossible to study them in the familiar thin section used for the study of rock specimens. As a result, therefore, a smooth surface of the material instead of a thin section is prepared, and all the technique available is utilized to make that surface a true plane devoid of relief. The treatment of the ore sample consists in cutting the specimen and grinding and polishing the cut surface. The grinding and polishing processes call for experimentation with abrasives and for many refinements of method. Accom-

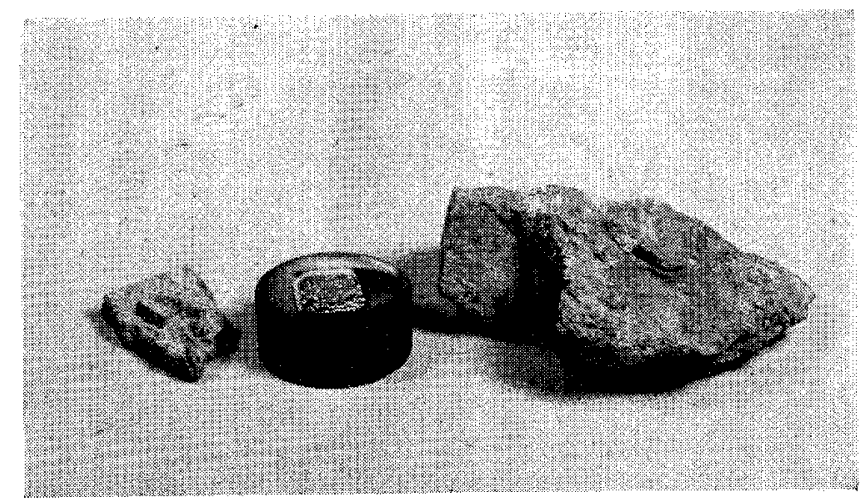

Fig. I Successive steps in the preparation of a polished section of an ore specimen. A small chip (on the left) has been cut from the hand specimen (on the right) by the use of a diamond-coated saw. In the center is a finished section of another chip mounted in bakelite and polished. panying illustrations show the steps used in preparing a specimen for polishing. Current technique by which a surface with a satisfactory high degree of polish is prepared with reasonable expenditure of time and effort is the result of long experimentation by $\mathrm{Mr}$. Rudolf von Huene in the geological laboratories of the Institute.

Although polished sections were first used in the study of opaque minerals in 1864, application of the method was slow in developing, and only within relatively recent years has it come into general use. In consequence, much still remains to be done and the techniques and methods have not outgrown the experimental stage. Parallel with the improved procedures in the study of polished sections has come a specialized technique in the microchemical analysis of ore minerals, made necessary by inherent difficulties in identifying minerals on polished surfaces. Application of this technique and its improvement have progressed in the geological laboratories at the Institute. At present, however, there is need especially for a perfecting of the qualitative chemical analyses, and perhaps of quantitative analyses on a microscopic scale.

In the first step of a microchemical analysis of an ore mineral, a suitable solvent dissolves a tiny grain of mineral scarcely larger than the point of a pin. The single drop of solution is then subjected to chemical manipulations, and the results are observed under the lens of a microscope. These results are for the most part only qualitative, but many of the tests are so sensitive as to afford opportunity to detect traces of impurities in what had been considered to be pure minerals. The frequent occurrence of impurities is of course important. Obviously, it would be still more important to know the exact amount of each constituent, within reasonable limits of error.

However, identifying the minerals is only a means to an end, for eventually the question, "How did it get that way?", must be answered. The second stage of geologic learning, the study of the space relations, moves more rapidly. Long before the student has acquired ability to identify all the minerals, he has noted that they occur in many strange patterns. Interpreting the

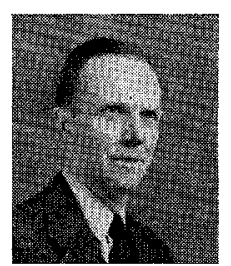

James A. Noble received his undergrad. uate and graduate training at Harvard University, stretching four degrees over 19 years. Between A.B. and S.B. degrees in geology and mining engineering in 1920 and 1922, and the M.A. and Ph.D. in geology in 1936 and 1939, Dr. Noble served as mining geologist for zinc mines in Tennessee, copper-zinc-lead-silver mines in Peru, and gold mines in Canada and South $\mathrm{Da}$ kota. Before coming to the Institute in 1947 he was for 16 years chief geologist at the Homestake Mine in the Black Hills of South Dakota, one of the large gold mines of the world. Dr. Noble's position at CIT as lecutrer in metalliferous geology represents his first official teaching experience.

During the recent war Dr. Noble did geological work for the Government in a cooperative effort between the Homestake Mining Co. and the U. S. Geological Survey in exploring deposits of vanadium in Idaho and manganese in Baja California. 
